ORIGINAL RESEARCH PAPER

\title{
VALIDATION OF AN ANALYTICAL METHOD FOR THE DETERMINATION OF ACRYLAMIDE IN POTATO CHIPS AND FRENCH FRIES
}

\author{
MIOARA NEGOIȚĂ, ADRIANA LAURA MIHAI*, GABRIELA-ANDREEA HORNEȚ \\ National Research \& Development Institute for Food Bioresources, IBA Bucharest, \\ Chromatography Department, 6 Dinu Vintilă Street, District 2, 021102, Bucharest, Romania \\ "corresponding author: mihai_laura21@yahoo.com \\ Received on 27 March 2021 \\ Revised on 16 April 2021
}

\begin{abstract}
The aim of this study was to validate a GC-MS/MS method for determining acrylamide (AA) in potato-based products by using the solid-phase extraction (SPE) clean-up. The method consisted in defatting the sample (potato chips, French fries) with hexane, extraction of AA in water, centrifugation, followed by AA purification on two SPE columns. The purified extract was derivatized with bromine compounds, then extracted with ethyl acetate: hexane mixture. The residue dissolved in ethyl acetate and triethylamine was injected into the GC-MS/MS. The method showed a good precision $\left(\mathrm{RSD}_{\mathrm{r}}=1.13-4.26 \% ; \mathrm{RSD}_{\mathrm{R}}=1.19-8.84 \%\right)$ and accuracy (recovery $=85.64-109.22 \%$ ). The precision of the results was demonstrated by participation in two proficiency tests launched by the FAPAS ${ }^{\circledR}$ program, yielding $\mathrm{z}$-scores of -0.8 (for pre-cooked French fries) and 0 (for potato crisps). Good sensitivity was achieved for potato chips with a LOD and LOQ of 6.94 and $20.83 \mu \mathrm{g} / \mathrm{kg}$, while for French fries, it was 10.29 and $30.87 \mu \mathrm{g} / \mathrm{kg}$, respectively. When applying the method on potato chips sample, the AA level varied between undetectable and $1504.93 \mu \mathrm{g} / \mathrm{kg}$, while for French fries was between $31.45-371.30 \mu \mathrm{g} / \mathrm{kg}$. The method fulfilled the performance criteria of Commission Regulation EU 2017/2158 for the determination of AA in potato-based products.
\end{abstract}

Keywords: acrylamide, French fries, potato chips, potato products

\section{Introduction}

Acrylamide (AA) is a product of the Maillard reaction and is formed when foods containing asparagine and reducing sugars are heated to temperatures above $120^{\circ} \mathrm{C}$ (EFSA, 2015).

In April 2002, scientists from the Swedish National Food Agency (SNFA) together with those from Stockholm University reported for the first time that the AA level

https://doi.org/10.35219/foodtechnology.2021.1.05 
of regular foods consumed by humans is higher than the level allowed in drinking water (Tareke et al., 2002; SNFA, 2002). In particular, potato products have been identified in many studies (Michalak et al., 2011; Sanny et al., 2012; Mesías et al., 2019 ) as having high concentrations of AA. FAO/WHO (2011) reported AA levels ranging between 399 and $1202 \mu \mathrm{g} / \mathrm{kg}$ for potato chips, and between 159 and 963 $\mu \mathrm{g} / \mathrm{kg}$ for French fries. In 2011, the mean dietary AA intake estimated by FAO/WHO (2011) for adults and children was between 1 and $4 \mu \mathrm{g} / \mathrm{kg}$ bodyweight/day. It was noted that children have a dietary AA exposure at least twice as high as the adult consumers when expressed on a bodyweight basis (FAO/WHO, 2011). Foods that contribute the most to the dietary intake will vary from country to country, according to different dietary patterns and how foodstuffs are processed and prepared. However, several AA intake studies indicate that food commodity that contribute the most to dietary AA exposure are fried potato products (French fries and potato crisps), bakery products, coffee, and breakfast cereals (Wilson et al., 2006; Mestdagh et al., 2008; Mojska et al., 2010; FAO/WHO, 2011; EFSA, 2015).

Thus, since 2002, laboratories around the world have begun to establish analytical methods in order to detect AA and assess human exposure to this harmful compound. It is therefore important to develop and validate sensitive and accurate analytical methods for the AA determination in different food products at a low level. For this reason, different GC-MS methods based on bromine derivatization (Nemato et al., 2002; Pittet et al., 2004; Dias et al., 2017) and without derivatization (Jezussek and Schieberle, 2003), or based on LC-MS using derivatization with mercaptobenzoic acid (Jezussek and Schieberle, 2003) and without derivatization (Roach et al., 2003; Andrzejewski, 2004; Delatour et al., 2004; Şenyuva and Gökmen, 2005, 2006) have been developed. The method performance depends very much on the sample preparation, especially on the AA extraction and purification, which have a great impact on the results. Usually, the most used procedures applied for sample preparation fail when there are complex food matrices, because of the inability to eliminate the presence of interferences, caused by co-eluents with the analyte, thus preventing the correct quantification (Delatour et al., 2004).

Solid-phase extraction (SPE) procedure used for AA extraction from food matrices has many advantages compared to other traditional techniques: a smaller amount of solvent is necessary, the preparation procedure involves only few steps which determines the reduction of analytical costs. Through the SPE technique, isolation, concentration and purification take place.

The aim of this study was to validate a sensitive and reliable GC-MS/MS method for determining the AA level in potato-based products by applying the SPE technique for sample preparation.

\section{Materials and methods Samples}

Three potato-based reference materials (RM) were used. One pre-cooked French fries RM (T3085QC, assigned value at $229 \mu \mathrm{g} / \mathrm{kg}$, range for $|\mathrm{z}| \leq 2=137-320 \mu \mathrm{g} / \mathrm{kg}$ ) 
and two potato crisps RM (T3089QC, assigned value at $206 \mu \mathrm{g} / \mathrm{kg}$, range for $|\mathrm{z}| \leq 2$ $=122-289 \mu \mathrm{g} / \mathrm{kg}$; TET043RM, assigned value at $625 \pm 45 \mu \mathrm{g} / \mathrm{kg}, \mathrm{k}=2$ ) were purchased from Fera Science Ltd (Sand Hutton, York).

Eight samples of French fries (ready-to-eat) (purchased from the fast-foods market from Bucharest, Romania) and six samples of potato chips (acquired from local supermarkets, Romania) were analyzed. The samples were chosen from the very consumed French fries and chips brands. For the protection of commercial interests, the French fries samples were coded with the letters FF and numbers from 1 to 8 , and the potato chips samples were noted with the letters PC and numbers from 1 to 6 , respectively.

In order to validate the method, two certified reference test materials: acrylamide in French fries (pre-cooked) - T3095/2019 (assigned value at $75.4 \mu \mathrm{g} / \mathrm{kg}$ AA with a satisfactory range of $42.2-109 \mu \mathrm{g} / \mathrm{kg}$ ) and acrylamide in potato crisps- T3099/2020 (assigned value at $156 \mu \mathrm{g} / \mathrm{kg}$ AA with a satisfactory range of $89.7-221 \mu \mathrm{g} / \mathrm{kg}$ ) purchased from the Food Analysis Performance Assessment Scheme (FAPAS) Food Chemistry Proficiency Tests (Sand Hutton, York) were used.

\section{Chemicals}

Native acrylamide (min. 99\% purity) and internal standard (IS) of labeled acrylamide $\left(1,2,3-{ }^{13} \mathrm{C}\right.$ labeled AA, min. $99 \%$ purity) were used. All others chemicals, reagents and solvents were of analytical grade.

Isolute ${ }^{\circledR}$ Multimode $(1000 \mathrm{mg}, 6 \mathrm{~mL})$ and Isolute ${ }^{\circledR} \mathrm{ENV}^{+}(500 \mathrm{mg}, 6 \mathrm{~mL}) \mathrm{SPE}$ cartridges were supplied by Biotage (Uppsala, Sweden).

\section{Standards and reagents}

Stock solution and working solutions of AA and IS were prepared as described by Negoiţă et al. (2020). The working standard solutions for linear calibration were prepared by diluting the working solution to the concentration sequences of 0.05 ; $0.10 ; 0.20 ; 0.30 ; 0.40 ; 0.50 ; 0.75 ; 1 ; 2 ; 3 \mathrm{mg} / \mathrm{L}$. All solutions were spiked with 440 $\mu \mathrm{L}$ IS $(1 \mathrm{mg} / \mathrm{L})$. Saturated bromine water solution and sodium thiosulphate solution $1 \mathrm{~mol} / \mathrm{L}$ were prepared according to Pittet et al. (2004).

\section{Sample preparation}

The procedure for sample preparation was according to the SPE method described previously by Negoiță et al. (2020). Briefly, $1 \mathrm{~g}$ of milled and homogenized sample was weighed into $50 \mathrm{~mL}$ centrifuge tubes.

The extraction method was carried out as follows: $440 \mu \mathrm{L}$ IS solution $(1 \mathrm{mg} / \mathrm{L}), 20$ $\mathrm{mL}$ water, and $10 \mathrm{ml}$ of $\mathrm{n}$-hexane were added to the sample which was vortexed at the ambient temperature for $60 \mathrm{~min}$. After centrifugation at $5^{\circ} \mathrm{C}, 6000 \mathrm{x} \mathrm{g}$ for $20 \mathrm{~min}$ (5804R Eppendorf centrifuge with cooling, Eppendorf, Germany), the aqueous phase $(\sim 10 \mathrm{~mL})$ was collected, avoiding the top fatty layer if present.

For the samples clean-up, the HyperSep Universal Vacuum Solid Phase Extraction Manifold from Thermo Fisher Scientific (USA) and two types of SPE columns were used. Firstly, SPE column Isolute ${ }^{\circledR}$ Multimode was conditioned with $\mathrm{MeOH}(3 \mathrm{~mL})$ and water $(3 \times 4 \mathrm{~mL})$. Afterwards, the aqueous extract $(\sim 10 \mathrm{~mL})$ collected previously 
was passed through the column and collected. The second SPE column Isolute ${ }^{\circledR}$ $\mathrm{ENV}^{+}$was conditioned with $\mathrm{MeOH}(5 \mathrm{~mL})$ and water $(5 \mathrm{~mL})$. The extract collected from the previous column was loaded and the eluate was discarded. The column was rinsed with water $(4 \mathrm{~mL})$. After rinsing, AA was collected from the column with $60 \% \mathrm{MeOH}$ in water $(5 \mathrm{~mL})$.

The purified AA extract was derivatized as previously described by Negoită et al. (2020).

\section{Preparation of the calibration solutions}

Ten calibration solutions in the range of $0.05-3 \mathrm{mg} / \mathrm{L}$ were prepared as described by Negoiță and Culețu (2016). The procedural blank was prepared identically to the sample, including the use of SPE clean-up.

Acrylamide determination by gas chromatography and tandem mass spectrometry The acrylamide quantification was performed by using a gas-chromatograph (TRACE GC ULTRA) coupled to a triple quadrupole mass spectrometer (TSQ Quantum XLS), both from Thermo Fisher Scientific (USA). An automatic injector (Right PTV) and a TriPlus AS autosampler (Thermo Fisher Scientific, USA) were used for sample injection. A capillary column (TraceGOLDTM TG-WaxMS, $30 \mathrm{~m}$ x $0.25 \mathrm{~mm}$ i.d. x $0.25 \mu \mathrm{m}$ film thickness) based on polyethylene-glycol was used.

As carrier gas, helium $(1.6 \mathrm{ml} / \mathrm{min})$ was used.

The sample injection volume was $1 \mu \mathrm{L}$, while the injector temperature was $220^{\circ} \mathrm{C}$. The oven temperature was set to $65^{\circ} \mathrm{C}$ and maintained for $1 \mathrm{~min}$, then increased with $15^{\circ} \mathrm{C} / \mathrm{min}$ to $170^{\circ} \mathrm{C}$, to $200^{\circ} \mathrm{C}$ with $5^{\circ} \mathrm{C} / \mathrm{min}$, to $240^{\circ} \mathrm{C}$ with $40^{\circ} \mathrm{C} / \mathrm{min}$, and hold for $15 \mathrm{~min}$ at $240^{\circ} \mathrm{C}$. The transfer line was set at $230^{\circ} \mathrm{C}$.

For the mass-spectrometer, the electron energy was $70 \mathrm{eV}$ (EI mode) and the acquisition mode was Selected Reaction Monitoring (SRM). The ion fragmentation was achieved with argon (1 mTorr) and for 2-BPA quantification $\mathrm{m} / \mathrm{z} 70$ was used, while for 2-BP $\left({ }^{13} \mathrm{C}_{3}\right) \mathrm{A}$ quantification $\mathrm{m} / \mathrm{z} 73$ was used. The AA content of tested potato-based products was calculated based on the ratio of the peak areas corresponding to the ions with $\mathrm{m} / \mathrm{z} 70$ and 73 .

All samples were analyzed and quantified in duplicate.

\section{Validation procedure}

The performance parameters (linearity, sensibility (LOD and LOQ), selectivity, precision, accuracy, robustness, and measurement uncertainty) were assessed according to the guides and recommendations for methods validation (ISO/IEC 17025, 2018; ICH, 2005; VICH, 2015; EC 2002/657/CE; ISO/TS 21748, 2004).

\section{Linearity}

\section{Standards}

The linearity of the method was estimated with the aid of a regression line on two calibration curves with six calibration levels each by the method of least squares. Ten standard solutions were simultaneously prepared and treated in parallel with the sample, without being purified by SPE. The quantity of IS of $440 \mu \mathrm{L}(1 \mathrm{mg} / \mathrm{L})$ was added for all samples and standards. 
To estimate the linearity of the curve, the relative standard deviation (RSD) in repeatability conditions should be within the limits of $\pm 15 \%$ for all the investigated levels. The analytical curves were considered linear for a value of regression coefficient $\left(\mathrm{R}^{2}\right)$ higher than 0.99 .

\section{Real Samples}

The linearity of the method in real samples was evaluated by plotting the ratio of the peak area of 2-BPA and 2-BP $\left({ }^{13} \mathrm{C}\right) \mathrm{A}$ versus the concentration of 2-BPA. Linearity range was evaluated also on real samples spiked with native AA solution $(10 \mathrm{mg} / \mathrm{L})$ at different levels of concentration: $0,250,500,750$ and $1000 \mu \mathrm{g} / \mathrm{kg}$ for ready-to-eat French fries, and $0,375,750$ and $1125 \mu \mathrm{g} / \mathrm{kg}$ for potato chips. The samples were treated as described for the overall method and injected twice into GC-MS/MS. The correlation was assessed to be linear for a value of the $\mathrm{R}^{2}$ higher than 0.99 .

\section{$L O D$ and $L O Q$}

The limit of detection (LOD) and limit of quantification (LOQ) of the method were evaluated using the calibration curve parameters (ICH, 2005).

Furthermore, LOD and LOQ were calculated on real samples of French fries and potato chips, by evaluating the AA content of some RM: T3085QC and TET043RM. By using these RM, 6 - 7 parallel samples were performed based on the newly developed procedure, using the SPE technique. All samples (initial extracts) were injected into GC-MS/MS and then quantified based on the calibration curve. For each initial extract several dilutions were made $(D=1 / 7$ for $\mathrm{T} 3085 \mathrm{QC}$ and $\mathrm{D}=1 / 20$, $\mathrm{D}=1 / 30$ for TET043RM). The diluted extracts were injected into GC-MS/MS and then quantified based on the calibration curve. Mean concentrations, SD, RSD, bias, and recovery were calculated.

In order to have good precision, LOQ (expressed as RSD) should be $\leq 20 \%$, while accuracy (expressed as recovery) should be in the range of $80-120 \%$ (ICH, 2005).

\section{Selectivity}

Selectivity was investigated by studying the possible interference given by AA in French fries and potato chips samples by using the SRM detection.

\section{Precision}

The method precision was investigated by repeatability, reproducibility and intermediary precision.

Precision was expressed as RSD (\%). The criteria imposed for RSD were according to the requirements set by the Commission Regulation (EU) 2017/2158. For the injection repeatability, 9 or 10 consecutive injections were carried out, for withinday precision 5-8 repeated analyses of the same sample were done, while for between-day precision samples were analyzed in 3-5 different days.

\section{Accuracy (recovery, bias)}

The need to assess the performance of the analytical methods to measure AA in foods led to the availability of commercial RM. In this respect, the Central Sciences Laboratory, through its FAPAS program, provides several RM, including French- 
fries and potato chips. To evaluate the accuracy of the method the TET043RM, T3095, and T3085QC material from FAPAS were used.

The accuracy of the method was investigated by recovery for RM of French fries (pre-cooked) (T3095; T3085QC), for one reference test material for potato chips (TET043RM) and for one sample of potato chips from the local supermarkets in Bucharest.

For the recovery evaluation, samples of French fries were fortified with working solution I of AA at concentrations of $0,250,500,750$, and $1000 \mu \mathrm{g} / \mathrm{kg}$, while for potato chips working solutions I of AA of concentrations $0,375,750$, and $1125 \mu \mathrm{g} / \mathrm{kg}$ were added and minimum 5 repeated analyses were performed.

The samples were treated as described for the overall method and injected twice on GC-MS/MS. According to the requirements of Commission Regulation (EU) 2017/2158, the recovery must be between $75-110 \%$.

Also, the accuracy of the method was evaluated with bias measurements using a RM of potato crisps (TET043RM), which presents an assigned AA value of $625 \mu \mathrm{g} / \mathrm{kg}$ and an uncertainty of $45 \mu \mathrm{g} / \mathrm{kg}(\mathrm{k}=2)$. The $\mathrm{RM}$ was prepared during the validation study by applying the SPE clean-up procedure, on the same day or different days, by the same analyst or different analysts, on the same equipment. The bias was calculated using the equation:

Bias $=($ obtained result - expected result $) \times 100 /$ expected result.

\section{Robustness}

In order to test the robustness of the developed method, samples of T3085QC, FAPAS 3095/2019 and potato chips (P3) were used and the following parameters were varied: extraction capacity of SPE columns used to purify the AA extract (Isolute $\mathrm{ENV}^{+} 500 \mathrm{mg} / 6 \mathrm{~mL}$ and Isolute $\mathrm{ENV}^{+} 1000 \mathrm{mg} / 6 \mathrm{~mL}$ ) and the amount of the sample taken into the study. The requirements for acceptability are the same as those for repeatability: $\mathrm{RSD}_{\mathrm{r}} \leq 0.66 \mathrm{x} \mathrm{RSD}_{\mathrm{r}_{-} \text {Horwitz. }}$.

\section{Measurement uncertainty}

The uncertainty budget was evaluated according to the ISO/IEC Guide 98-3 (2008) and EURACHEM/CITAC guide (2011). The uncertainty obtained was verified by the FAPAS tests performed.

\section{Method application}

The validated method applicability was evaluated by analyzing eight French fries samples and six potato chips samples.

\section{Statistical analysis}

AA content of analyzed samples was expressed as mean \pm standard deviation. Regarding the validation parameters, the mean for the concentration values expressed in $\mu \mathrm{g} / \mathrm{kg}$, standard deviation in repeatability/reproducibility conditions $\left(\mathrm{SD}_{\mathrm{r}} / \mathrm{SD}_{\mathrm{R}}\right)$ expressed in $\mu \mathrm{g} / \mathrm{kg}$ as well as $\mathrm{RSD}$ in repeatability/reproducibility conditions $\left(\mathrm{RSD}_{\mathrm{r}} / \mathrm{RSD}_{\mathrm{R}}\right)$ expressed in \% were calculated using Microsoft Excel.

An AA content below LOQ $(30.87 \mu \mathrm{g} / \mathrm{kg}$ for French fries and similar products, and $20.83 \mu \mathrm{g} / \mathrm{kg}$ for potato chips and similar products) was considered undetectable. 


\section{Results and discussion}

\section{Method development}

Based on the published researches in this field (Nemato et al., 2002; Pittet et al., 2004; Fernandes and Soares, 2007; Negoiță and Culețu, 2016) as well the standard SR EN 16618 (2015) a GC-MS/MS method was developed for AA determination from processed potato products, by applying an improved sample preparation based on SPE-technique (Negoiță et al., 2020). Briefly, AA was extracted from pre-fried potatoes and chips samples, with water at room temperature and then degreased with hexane. The aqueous phase was purified by SPE and derivatized with bromine compounds. At the end, the AA dibromide compound was extracted with a mixture of solvents (ethyl acetate: hexane 4:1, v/v) and analyzed at GC-MS/MS in SRM mode.

The analytical separation of AA was performed using a TraceGOLDTM TGWaxMS capillary column. Figure 1 presents the chromatograms of the French fries pre-cooked sample (FF8) with an AA content of $371.30 \mu \mathrm{g} / \mathrm{kg}$, and also the Potato chips sample (PC5) with an AA content of $157.79 \mu \mathrm{g} / \mathrm{kg}$.

\section{$G C-M S / M S-S P E$ method assessment}

Previous studies shown that tandem MS/MS with electron impact positive ionization mode $\left(\mathrm{EI}^{+}\right)$is a powerful tool for the detection of AA in foods at low levels (Tareke et al., 2002).

Prior to AA analysis from potato-based products, the GC-MS/MS - SPE method was validated to evaluate the method performance requirements set by the Commission Regulation (EU) 2017/2158. The method's validation parameters evaluated were linearity, sensibility (LOD, LOQ), selectivity, accuracy (as recovery and bias), precision, robustness and measurement uncertainty.

\section{Linearity}

\section{Standards}

Calibration curves (Figures 2 and 3) were constructed by plotting the AA/IS area ratio versus the concentration of AA in the standard, the ratio of the peak area of 2$\mathrm{BPA}$ and $2-\mathrm{BP}\left({ }^{13} \mathrm{C}\right) \mathrm{A}$ versus the concentration of 2-BPA. The regression coefficients $\left(R^{2}\right)$ were $\geq 0.999(n=3)$.

For all the studied calibration levels, the $\mathrm{RSD}_{\mathrm{r}}$ were within the limits of $\pm 15 \%$, ranging between 0.17 and $4.02 \%$.

\section{Real Samples}

The AA content of the samples was quantified using the ion at $\mathrm{m} / z 70$ for 2-BPA, and the ion at $m / z 73$ for $2-\mathrm{BP}\left({ }^{13} \mathrm{C}_{3}\right) \mathrm{A}$. The linearity of the method in the real samples was evaluated by plotting the peak area ratios (70/73) against the corresponding ratios of the analyte amounts. Table 1 shows the linearity range of French fries and potato chips, which demonstrated by the regression coefficient obtained $\left(\mathrm{R}^{2} \geq 0.99\right)$ that there is a linearity between the response factor (corrected area) and the AA concentration in the case of the French fries samples (pre-cooked and ready-to-eat) 
in the range of $0.07-2.62 \mathrm{mg} / \mathrm{L}(30.58-1152.88 \mu \mathrm{g} / \mathrm{kg})$ and for the potato chips in the range of $0.05-3.43 \mathrm{mg} / \mathrm{L}(21-1863.99 \mu \mathrm{g} / \mathrm{kg})$, respectively.
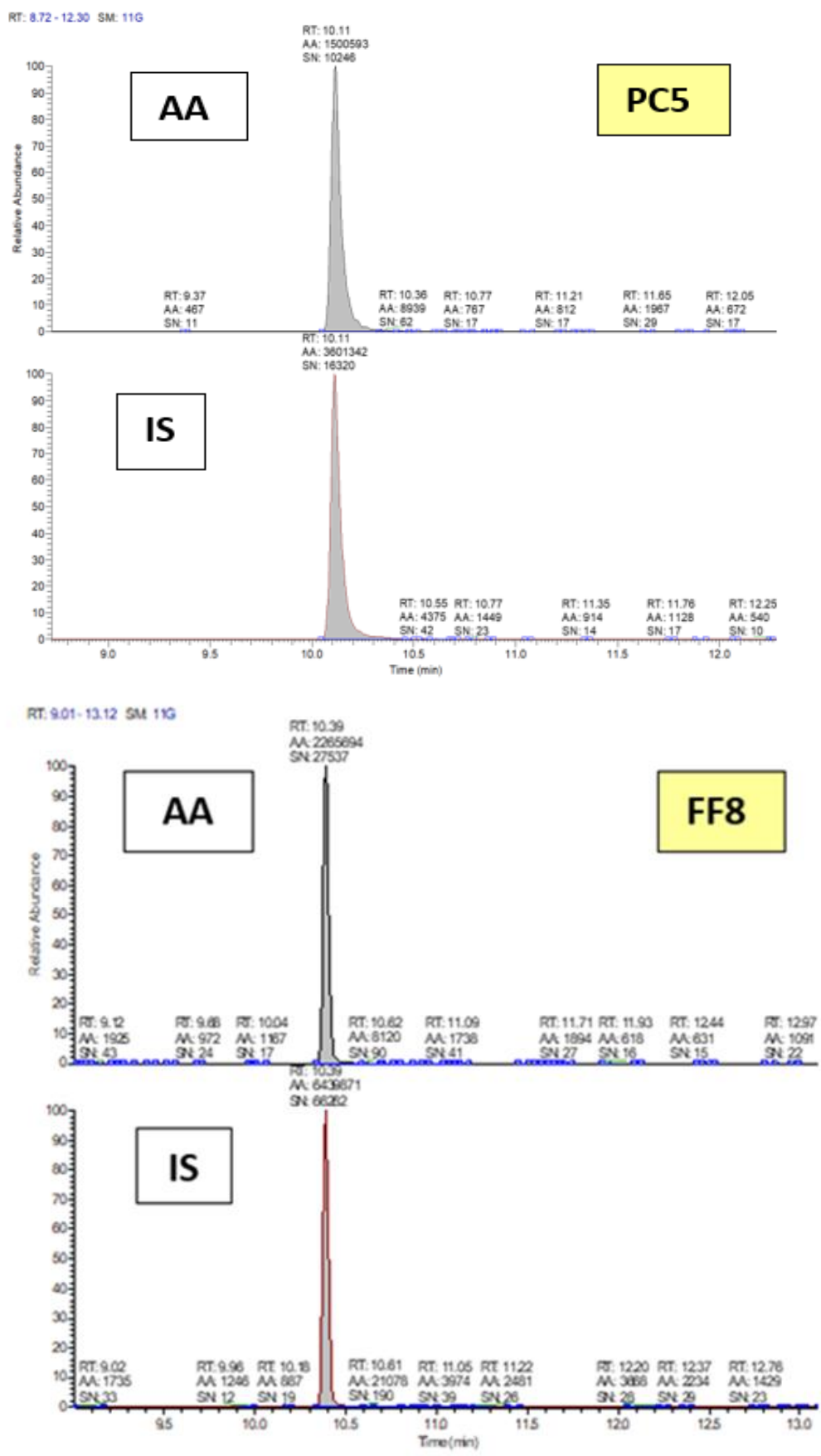

Figure 1. Chromatograms of potato chips samples (PC5 - $157.79 \mu \mathrm{g} / \mathrm{kg}$ ) and French fries pre-cooked sample (FF8 - $371.30 \mu \mathrm{g} / \mathrm{kg}$ ) (AA- acrylamide peak, IS - labeled acrylamide peak). 
$Y=0.183676+2.22819^{*} \times \bar{R}^{\wedge} 2=0.9995 W$. Equal

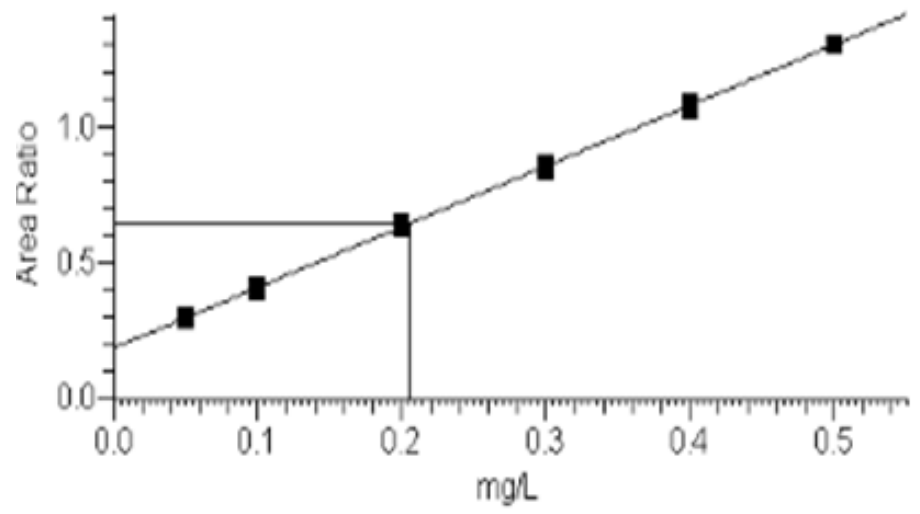

Figure 2. Calibration curve for AA, $0.05-0.5 \mathrm{mg} / \mathrm{L}$.

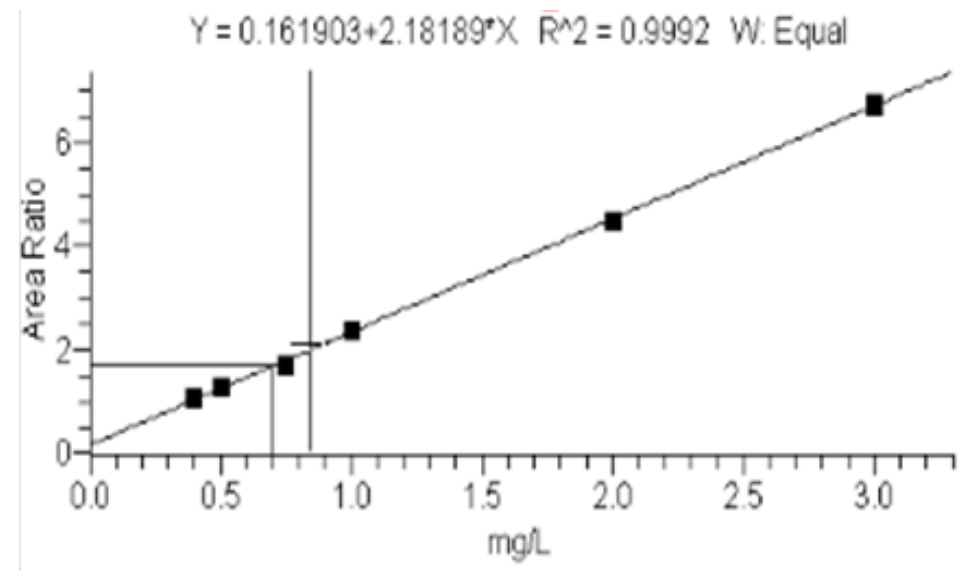

Figure 3. Calibration curve for AA, $0.4-3 \mathrm{mg} / \mathrm{L}$.

\section{$L O D$ and $L O Q$}

By using the calibration curve, LOD of $0.008 \mathrm{mg} / \mathrm{L}$ and LOQ of $0.024 \mathrm{mg} / \mathrm{L}$ were obtained. By using RM and by successive dilutions of their extracts, in the case of French fries and similar products were established LOD and LOQ values of 10.29 and $30.87 \mu \mathrm{g} / \mathrm{kg}$, while for the potato chips and similar products it was 6.94 and $20.83 \mu \mathrm{g} / \mathrm{kg}$, respectively.

LOQ values fulfilled the criteria defined in the Commission Regulation (EU) 2017/2158.

\section{Selectivity}

The selectivity of the developed method was investigated by chromatographic separation of AA in the presence of other compounds from the pre-cooked French fries, ready-to-eat French fries, and potato chips. The SRM detection and the use of IS in the method led to a specific analysis. 
Table 1. Linearity of the method in real samples - AA area/IS area $v s$. the amount of AA.

\begin{tabular}{|c|c|c|c|}
\hline \multicolumn{2}{|l|}{ Parameter } & \multirow{2}{*}{$\begin{array}{l}\text { French fries } \\
0.07-2.62\end{array}$} & \multirow{2}{*}{$\begin{array}{l}\text { Potato Chips } \\
0.05-3.43\end{array}$} \\
\hline Linear range & $\mathrm{mg} / \mathrm{L}$ & & \\
\hline & $\mu \mathrm{g} / \mathrm{kg}$ & $30.58-1152.88$ & $21-1863.99$ \\
\hline \multicolumn{2}{|c|}{ Regression equation $^{\mathrm{x}}$} & $Y=2.4182 \cdot X+0.0152$ & $Y=2.2198 \cdot X+0.0802$ \\
\hline \multicolumn{2}{|c|}{ Number of data points ${ }^{y}$} & 28 & 24 \\
\hline \multicolumn{2}{|c|}{ Regression coefficient $\left(R^{2}\right)$} & 0.9988 & 0.9989 \\
\hline \multicolumn{2}{|c|}{ Correlation coefficient $(R)^{z}$} & 0.9994 & 0.9994 \\
\hline \multicolumn{2}{|c|}{ Residual standard deviation, $S_{\mathrm{y}}$} & 0.019148 & 0.007411 \\
\hline \multicolumn{2}{|c|}{ Standard deviation of the method, $\mathrm{S}_{\mathrm{x} 0}$} & 0.00792 & 0.00334 \\
\hline
\end{tabular}

\section{Precision}

Injection repeatability

For injection repeatability the $\mathrm{RSD}_{\mathrm{r}}$ ranged between $1.39-2.36 \%$ for measured concentration $(\mathrm{mg} / \mathrm{L}), 1.41-2.40 \%$ for area ratio, and $0.02-0.05 \%$ for retention time.

Within-day precision, between-day precision and intra-laboratory reproducibility

The obtained results are presented in table 2 .

Table 2. Within-day precision, between-day precision and intra-laboratory reproducibility of the developed method for determination of AA in potato-based samples.

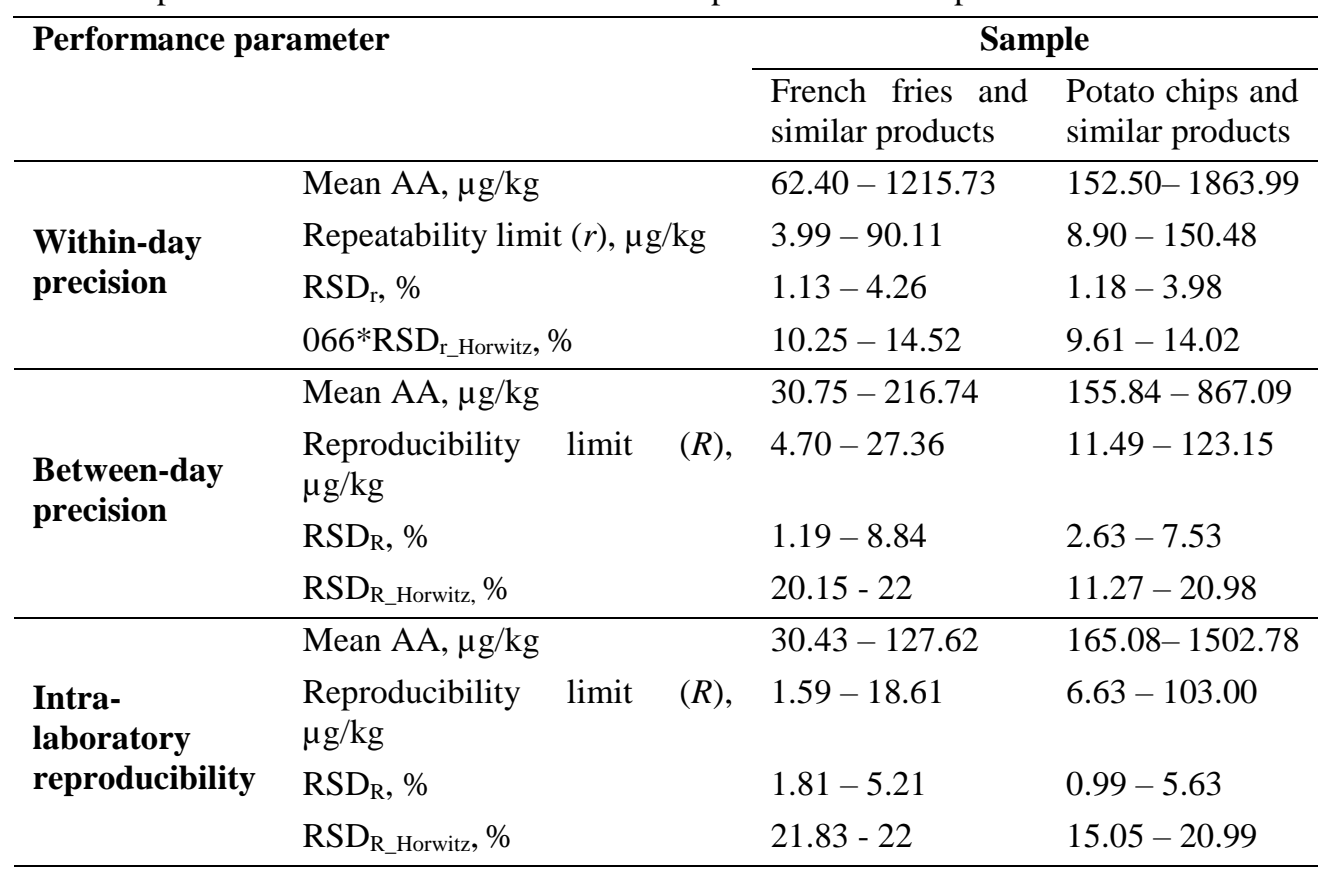




\section{Inter-laboratory reproducibility}

The laboratory participated in the inter-laboratory proficiency testing (Table 3) organized in 2019 (T3095/lab. no. 6) and 2020 (T3099/lab. no. 6) by the FAPAS program analyzing French fries (pre-cooked) and potato crisps test materials and received a z-score of -0.8 and 0 .

Results indicated that the GC-MS/MS- SPE method used for the AA quantification had a very good accuracy.

Table 3. Proficiency test results.

\begin{tabular}{lllll}
\hline Matrix & Proficiency test & $\begin{array}{l}\text { Assigned } \\
\text { value } \\
(\boldsymbol{\mu g} / \mathbf{k g})\end{array}$ & $\begin{array}{l}\text { Result } \\
(\mathbf{M e a n} \pm \mathbf{S D}),\end{array}$ & $\begin{array}{l}\text { z-score } \\
\boldsymbol{\mu g} / \mathbf{k g}[\mathbf{n}]^{\mathrm{x}}\end{array}$ \\
\hline $\begin{array}{l}\text { French Fries } \\
\text { (pre-cooked) }\end{array}$ & $\begin{array}{l}\text { FAPAS } \\
\text { T3095/2019 }\end{array}$ & 75.4 & $62.40 \pm 1.43[\mathrm{n}=6]$ & -0.8 \\
Potato crisps & $\begin{array}{l}\text { FAPAS } \\
\text { T3099/2020 }\end{array}$ & 156 & $156 \pm 4.10[\mathrm{n}=8]$ & 0 \\
\hline
\end{tabular}

${ }^{\mathrm{x}}$ number of the analysed samples

\section{Accuracy}

The obtained results from the assessment of accuracy, expressed by recovery, are presented in Table 4. Good percentage recoveries $(85.64-109.22 \%)$ were obtained with acceptable variation (RSD\% $=1.13-3.94 \%)$ according to the present method, fulfilling the required criteria (Commission Regulation (EU), 2017). These samples were also used to test the linearity of the method. Such results demonstrate the accuracy of the GC-MS/MS - SPE method used for the quantification of AA.

Similar results were obtained by Nemoto et al. (2002) who reported recoveries ranging between $97-105 \%$ for AA from spiked samples and the RSD ranging between $0.8-4 \%$.

The accuracy of the method expressed by bias, determined for the analyzed RM, TET043RM, with an assigned value of $625 \pm 45 \mu \mathrm{g} / \mathrm{kg}$ of AA was $2.85 \%$ (Table 5).

\section{Robustness}

To assess the robustness, several variations were used: the replacement in the purification stage of the $\mathrm{ENV}^{+} 500 \mathrm{mg} / 6 \mathrm{~mL}$ cartridges with $\mathrm{ENV}^{+} 1000 \mathrm{mg} / 6 \mathrm{~mL}$ and the change in the amount of the sample taken into study $(0.5 ; 1 ; 1.5 \mathrm{~g})$ did not lead to variations in the determined concentration. The value of obtained RSD was between 0.93 and $1.93 \%$.

\section{Measurement uncertainty}

The uncertainty of results for determining the AA level in French fries, potato chips and similar products by GC-MS/MS - SPE was $\pm 17.5 \%$ as determined by the uncertainty budget. This value was verified with the $\mathrm{z}$ scores obtained in the FAPAS tests, demonstrating that the uncertainty value is correctly estimated. 
Table 4. Recovery for the spiked samples by using the developed method.

\begin{tabular}{|c|c|c|c|c|c|c|}
\hline \multirow[b]{2}{*}{ Sample/code } & \multicolumn{3}{|c|}{ Acrylamide contents $(\mu \mathrm{g} / \mathrm{kg})$} & \multirow{2}{*}{$\begin{array}{l}\text { Recovery } \\
(\%)^{x}\end{array}$} & \multirow{2}{*}{$\begin{array}{l}\text { RSD }_{\mathbf{r}} \\
(\%)\end{array}$} & \multirow{2}{*}{$\begin{array}{l}\text { Number } \\
\text { of } \\
\text { samples } \\
\text { [n] }\end{array}$} \\
\hline & $\begin{array}{l}\text { Before } \\
\text { spiking }\end{array}$ & $\begin{array}{l}\text { Spiked } \\
\text { amount }\end{array}$ & After spiking & & & \\
\hline \multirow{4}{*}{$\begin{array}{l}\text { French } \\
\text { Fries (pre- } \\
\text { cooked)/ } \\
\text { T3095 }\end{array}$} & $64.51 \pm 1.10$ & 250 & $328.07 \pm 3.72$ & 105.43 & 1.13 & 7 \\
\hline & $62.09 \pm 2.57$ & 500 & $608.21 \pm 8.11$ & 109.22 & 1.33 & 6 \\
\hline & $74.98 \pm 2.73$ & 750 & $876.45 \pm 54.12$ & 106.93 & 1.97 & 6 \\
\hline & $74.98 \pm 2.73$ & 1000 & $1152.89 \pm 32.18$ & 107.79 & 2.79 & 6 \\
\hline \multirow{4}{*}{$\begin{array}{l}\text { French } \\
\text { Fries (pre- } \\
\text { cooked)/ } \\
\text { T3085QC }\end{array}$} & $212.11 \pm 2.49$ & 250 & $458.58 \pm 6.06$ & 98.59 & 1.32 & 6 \\
\hline & $209.02 \pm 2.51$ & 500 & $657.74 \pm 16.09$ & 89.74 & 2.45 & 6 \\
\hline & $212.59 \pm 4.13$ & 750 & $910.79 \pm 17.08$ & 93.10 & 1.88 & 6 \\
\hline & $223.21 \pm 4.20$ & 1000 & $1215.73 \pm 15.90$ & 99.25 & 1.31 & 5 \\
\hline \multirow{3}{*}{$\begin{array}{l}\text { Potato } \\
\text { Crisps/ } \\
\text { TET043RM }\end{array}$} & $653.65 \pm 36.79$ & 375 & $974.81 \pm 27.50$ & 85.64 & 2.82 & 6 \\
\hline & $644.39 \pm 29.72$ & 750 & $1362.95 \pm 53.74$ & 95.81 & 3.94 & 5 \\
\hline & $688.24 \pm 14.10$ & 1225 & $1863.99 \pm 49.47$ & 104.51 & 2.65 & 6 \\
\hline \multirow{3}{*}{$\begin{array}{l}\text { Potato } \\
\text { Chips }^{\mathrm{y}}\end{array}$} & $165.83 \pm 3.65$ & 375 & $564.45 \pm 22.46$ & 105.83 & 3.65 & 6 \\
\hline & $167.65 \pm 3.14$ & 750 & $927.73 \pm 10.99$ & 101.35 & 1.18 & 6 \\
\hline & $167.65 \pm 3.14$ & 1125 & $1313.73 \pm 24.80$ & 101.87 & 1.89 & 6 \\
\hline
\end{tabular}

${ }^{\mathrm{x}}$ Recovery $(\%)=(($ After spiking - Before spiking $) /$ Spiked amount $) \times 100$; ${ }^{\mathrm{y}}$ The sample of potato chips was obtained from the local supermarkets in Bucharest

Table 5. Accuracy expressed by bias for Potato Crisps - TET043RM.

\begin{tabular}{|c|c|}
\hline Parameter & Values \\
\hline Reference value (RV), $\mu \mathrm{g} / \mathrm{kg}$ & 625 \\
\hline Expanded uncertainty $U(\mathrm{k}=2)$ & 45 \\
\hline Found value (mean) $(M), \mu \mathrm{g} / \mathrm{kg}(\mathrm{n}=31)$ & 642.87 \\
\hline $\mathrm{SD}, \mu \mathrm{g} / \mathrm{kg}$ & 41.04 \\
\hline $\mathrm{RSD}_{\mathrm{R}},(\%)$ & 6.38 \\
\hline Bias $|\mathrm{RV}-\mathrm{M}|, \mu \mathrm{g} / \mathrm{kg}$ & 17.81 \\
\hline Bias $(|\mathrm{RV}-\mathrm{M}| \times 100) / \mathrm{RV}, \%$ & 2.85 \\
\hline
\end{tabular}

Comparing the performance parameters of the method used in this study with other similar methods from the literature (Şenyuva and Gökmen, 2006; Rufian-Henares et al., 2006; Fernandes and Soares, 2007; Lee et al., 2007; Mesías et al., 2015; Mesías et al., 2018) it is shown that the proposed method is comparable and accurate for the analysis of this chemical contaminant (Table 6). 


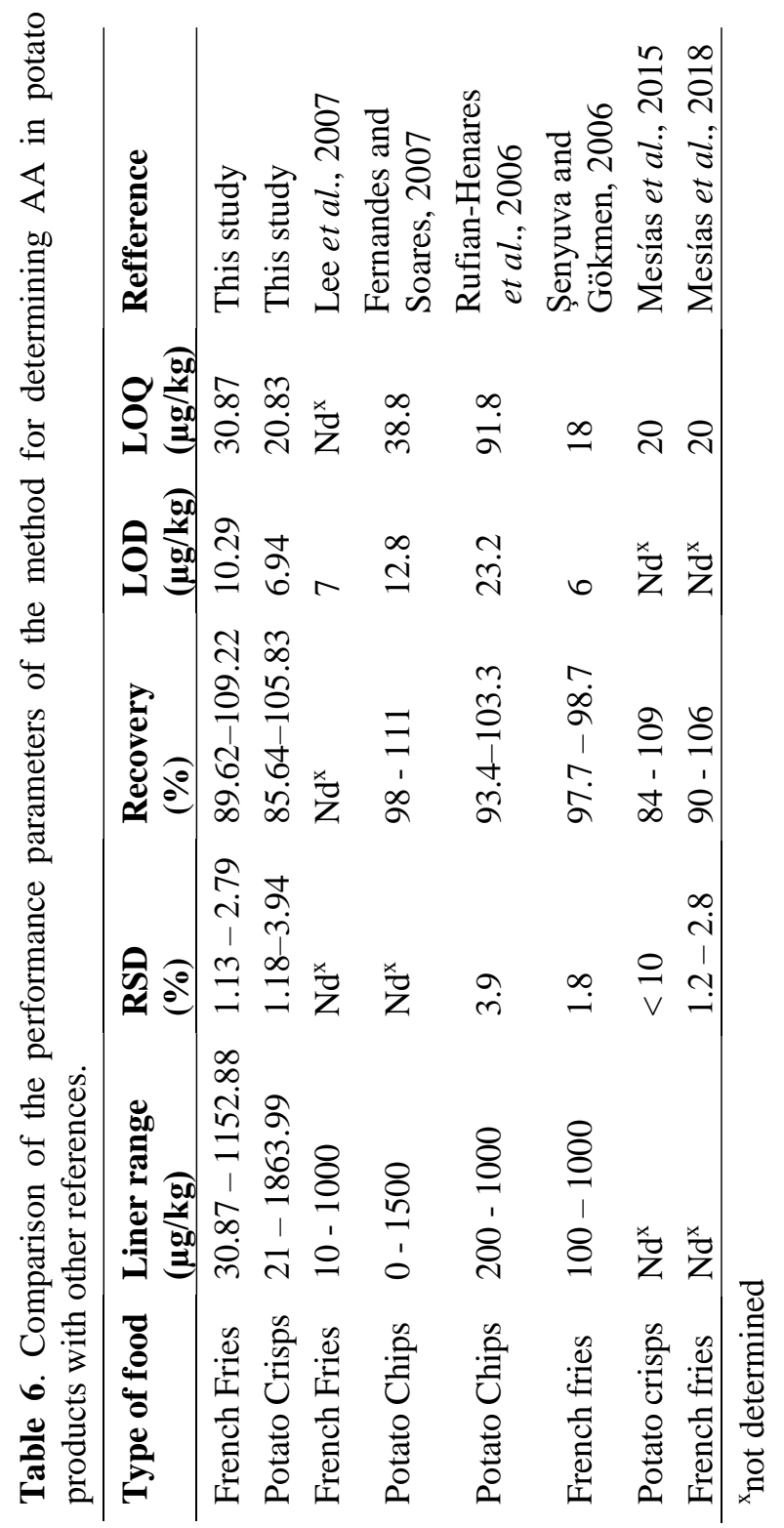

\section{Application Method}

Table 7 illustrates the AA content in different samples of potato chips and French fries, which varied between 31.45 and $371.30 \mu \mathrm{g} / \mathrm{kg}$ for French fries and between undetectable and $842.50 \mu \mathrm{g} / \mathrm{kg}$ for potato chips.

The AA levels of potato-based products depends on the quality of raw materials, food formulation and manufacturing conditions. 
Two (PC1, PC3) out of six varieties of potato chips showed higher values than the benchmark level of $750 \mu \mathrm{g} / \mathrm{kg}$ set for this product category by the Commission Regulation (EU) 2017/2158. For the PC3 sample, the AA level was two times higher than the benchmark level. No AA was detected in the PC6 assortment, and in three chips assortments (PC2, PC4, PC5) the AA level varied between 157.79-302.85 $\mu \mathrm{g} / \mathrm{kg}$. By analyzing the eight assortments of ready-to-eat French fries, the AA level was under the benchmark level of $500 \mu \mathrm{g} / \mathrm{kg}$ set by the Commission Regulation (EU) 2017/2158 for this product category.

Table 7. AA content of analyzed samples.

\begin{tabular}{cccc}
\hline Brand & Code/sample & $\begin{array}{c}\text { AA, } \boldsymbol{\mu g} / \mathbf{k g} \\
(\mathbf{m e a n} \pm \mathbf{S D}), \mathbf{n}=\mathbf{3}\end{array}$ & $\begin{array}{c}\text { Benchmark } \\
\text { level, } \boldsymbol{\mu g} / \mathbf{k g}\end{array}$ \\
\hline A & FF1 & $99.12 \pm 2.96$ & \\
B & FF2 & $76.42 \pm 4.65$ & \\
C & FF3 & $127.31 \pm 7.99$ & \\
D & FF4 & $31.45 \pm 1.55$ & 500 \\
E & FF5 & $89.16 \pm 1.42$ & \\
F & FF6 & $203.67 \pm 1.35$ & \\
G & FF7 & $198.00 \pm 34.65$ & \\
H & FF8 & $371.30 \pm 64.98$ & \\
I & PC1 & $842.50 \pm 40.51$ & \\
& PC3 & $1504.93 \pm 15.43$ & \\
J & PC2 & $302.85 \pm 2.11$ & 750 \\
K & PC5 & $157.79 \pm 9.74$ & \\
L & PC4 & $298.50 \pm 6.59$ & \\
${ }^{\times}$LOD $=6.94 \mu \mathrm{g} / \mathrm{kg} ;$ LOQ $=20.83 \mu \mathrm{g} / \mathrm{kg}$ & Undetected $^{\mathrm{x}}$ &
\end{tabular}

\section{Conclusions}

A GC-MS/MS-SPE method for the quantification of AA content from potato-based products was validated. This method offers a rapid quantitative procedure for AA determination and shows high sensitivity, good linearity and good reproducibility. The determined LOQ was below $50 \mu \mathrm{g} / \mathrm{kg}$, fulfilling the criteria established by the Commission Regulation (EU) 2017/2158.

The values of the performance parameters and the results of the FAPAS proficiency tests denote that the GC-MS/MS-SPE method can be applied for the determination of AA in many investigations.

\section{Acknowledgments}

This study was achieved through Core Programme (PN 19 02), with the support of the Ministry of Research and Innovation (MCI), contract 22N/2019, project PN 19 020301 . 


\section{References}

Andrzejewski, D., Roach, J.A.G., Gay, M.L., Musser, S.M. 2004. Analysis of coffee for the presence of acrylamide by LC-MS/MS. Journal of Agricultural and Food Chemistry, 52(7), 1996-2002.

Delatour, T., Périsset, A., Goldmann, T., Riediker, S., Stadler, R.H. 2004. Improved sample preparation to determine acrylamide in difficult matrixes such as chocolate powder, cocoa, and coffee by liquid chromatography tandem mass spectroscopy. Journal of Agricultural and Food Chemistry, 52, 4625-4631.

Dias, F.F.G., Bogusz Junior, S., Hantao, L.W., Augusto, F., Sato, H.H. 2017. Acrylamide mitigation in French fries using native L-asparaginase from Aspergillus oryzae CCT 3940. LWT- Food Science and Technology, 76, 222-229.

EFSA. 2015. Scientific opinion on acrylamide in food. EFSA Journal, 13(6), 4104.

Eurachem/CITAC Guide CG4. 2012. Quantifying Uncertainty in Analytical Measurement, UK, 3rd ed., 1-133.

European Commission (EU). 2017. Commission Regulation 2017/2158 of 20 November 2017 establishing mitigation measures and benchmark levels for the reduction of the presence of acrylamide in food. Official Journal of the European Union, L304, 24-44.

European Commission. 2002. Commission Decision of 12 August 2002 Implementing Council Directive 96/23/EC Concerning the Performance of Analytical Methods and the Interpretation of Results, (2002/657/CE), L 221/8-36.

FAO/WHO. 2011. Evaluation of certain contaminants in food: Seventy-second report of the Joint FAO/WHO Expert Committee on Food Additives. WHO Technical Report Series 959.

Fernandes, J.O., Soares, C. 2007. Application of matrix solid-phase dispersion in the determination of acrylamide in potato chips. Journal of Chromatography A, 1175, 1-6.

ICH. 2005. Validation of Analytical Procedures: Text and Methodology Q2(R1); ICH: London.

ISO/IEC 17025. 2018. General requirements for the competence of testing and calibration laboratories.

ISO/IEC Guide 98-3. 2008. Uncertainty of measurement - part 3: guide to the expression of uncertainty in measurement (GUM: 1995).

ISO/TS 21748. 2004. Guidance for the use of repeatability, reproducibility and trueness estimates in measurement uncertainty estimation.

Jezussek, M., Schieberle, P. 2003. A new LC/MS-method for the quantitation of acrylamide based on a stable isotope dilution assay and derivatization with 2-mercaptobenzoic acid. Comparison with two GC/MS methods. Journal of Agricultural and Food Chemistry, 51, 7866-7871.

Lee, M.R., Changa, L.Y., Dou, J. 2007. Determination of acrylamide in food by solid-phase microextraction coupled to gas chromatography- positive chemical ionization tandem mass spectrometry. Analytica Chimica Acta, 582, 19-23.

Mesías, M., Delgado-Andrade, C., Holgado, F, Morales, F.J. 2019. Acrylamide content in French fries prepared in food service establishments. LWT- Food Science and Technology, 100, 83-91. 
Mesías, M., Delgado-Andrade, C., Holgado, F., Morales, F.J. 2018. Acrylamide content in French fries prepared in households: A pilot study in Spanish homes. Food Chemistry, 260, 44-52.

Mesías, M., Morales, F.J. 2015. Acrylamide in commercial potato crisps from Spanish market: Trends from 2004 to 2014 and assessment of the dietary exposure. Food and Chemical Toxicology, 81, 104-110.

Mestdagh, F., Maertens, J., Cucu, T., Delporte, K., Van Peteghem, C., De Meulenaer, B. 2008. Impact of additives to lower the formation of acrylamide in a potato model system through $\mathrm{pH}$ reduction and other mechanisms. Food Chemistry, 107, 26-31.

Michalak, J., Gujska, E., Klepacka, J. 2011. The effect of domestic preparation of some potato products on acrylamide content. Plant Foods for Human Nutrition, 66, 307-312.

Mojska, H., Gielecińska, I., Szponar, L., Ołtarzewski, M. 2010. Estimation of the dietary acrylamide exposure of the Polish population. Food and Chemical Toxicology, 48, 20902096.

Negoiță, M., Culețu, A. 2016. Apllication of an accurate and validated method for identification and quantification of acrylamide in bread, biscuits and other bakery products using GC-MS/MS system. Journal of the Brazilian Chemical Society, 27(10), 1782-1791.

Negoiță, M., Mihai, A.L., Horneț, G.A., Duţă, D.E. 2020. Development of SPE clean-up procedure for acrylamide determination from potato-based products by GC-MS/MS. DE GRUYTER, Open Agriculture, 5, 305-316.

Nemoto, S., Takatsuki, S., Sasaki, K., Maitani, T. 2002. Determination of acrylamide in foods by GC/MS using 13C-labeled acrylamide as an internal standard. Journal of the Food Hygienic Society of Japan, 43(6), 371-376

Pittet, A., Périsset, A., Oberson, J.M. 2004. Trace level determination of acrylamide in cerealbased foods by gas chromatography-mass spectrometry. Journal of Chromatography A, 1035, 123-130.

Roach, J.A.G., Andrzejewski, D., Gay, M.L., Nortrup, D., Musser, S.M. 2003. Rugged LCMS/MS survey analysis for acrylamide in foods. Journal of Agricultural and Food Chemistry, 51, 7547-7554.

Rufian-Henares, J.A., Morales, F.J. 2006. Determination of acrylamide in potato chips by a reversed-phase LC-MS method based on a stable isotope dilution assay. Food Chemistry, 97, 555-562.

Sanny, M., Jinap, S., Bakker, E.J., van Boekel, M.A.J.S et al. 2012. Possible causes of variation in acrylamide concentration in French fries prepared in food service establishments: An observational study. Food Chemistry, 132, 134-143.

Şenyuva, H.Z., Gökmen, V. 2005. Study of acrylamide in coffee using an improved liquid chromatography mass spectrometry method: investigation of colour changes and acrylamide formation in coffee during roasting. Food Additives \& Contaminants, 22, 214-220.

Şenyuva, H.Z., Gökmen, V. 2006. Interference-free determination of acrylamide in potato and cereal-based foods by a laboratory validated liquid chromatography-mass spectrometry method. Food Chemistry, 97, 539-545.

SNFA. 2002. Acrylamide in food. Mechanisms of formation and influencing factors during heating of foods. Report from Swedish Scientific Expert Committee. 
SR EN 16618. 2015. Food analysis - Determination of acrylamide in food by liquid chromatography tandem mass spectrometry (LC-ESI-MS/MS).

Tareke, E., Rydberg, P., Karlsson, P., Eriksson, S., Törnqvist, M. 2002. Analysis of acrylamide, a carcinogen formed in heated foodstuffs. Journal of Agricultural and Food Chemistry, 50, 4998-5006.

VICH GL49. 2015. Guidance for Industry Studies to Evaluate the Metabolism and Residue Kinetics of Veterinary Drugs in Food- Producing Animals: Validation of Analytical Methods Used in Residue Depletion Studies, VICH: Rockville.

Wilson, K.M., Rimm, E.B., Thompson, K.M., Mucci, L.A. 2006. Dietary acrylamide and cancer risk in humans: a review. Journal für Verbraucherschutz und Lebensmittelsicherheit, 1, 19-27. 